\title{
O uso do transe extático no processo da adivinhação babilônica
}

\author{
EMANUEL BOUZON \\ Pontificia Universidade Católica do Rio de Janeiro
}

\begin{abstract}
RESUMO: Este artigo analisa uma série de textos cuneiformes da antiga Babilônia em vários de seus períodos. Sabe-se, por esses tabletes, que, além da adivinhação dedutiva, sem dúvida a mais abundantemente testemunhada, existiu um outro tipo de contato com a divindade: a adivinhação "inspirada", em que os deuses comunicavam a sua mensagem a um intermediário em estado de transe. Nos textos conhecidos este intermediário recebia o título de mahhüm ou muhhâm no caso de um homem e mahhûtum ou muhhûtum no caso de uma mulher.
\end{abstract}

PALAVRAS-CHAVE: Babilônia, adivinhação, transe extático, cuneiformes.

\section{Introdução}

A religião babilônica usava diferentes maneiras de entrar em contato com os deuses para conhecer a sua vontade e obter deles respostas para os diversos problemas da vida cotidiana. A adivinhação dedutiva ${ }^{1}$ era, sem dúvida, o método mais comum e mais popular para conhecer os desígnios dos deuses a respeito de um país, de uma cidade, de um soberano ou de uma pessoa qualquer ${ }^{2}$. Entre os métodos mais conhecidos deste tipo de adivinhação estão a hepatoscopia, que consistia no exame do figado dos animais sacrificados $^{3}$, a astrologia ${ }^{4}$, a interpretação do vôo das aves ${ }^{5}$, a lecanomancia ${ }^{6}$ etc... Neste gênero de adivinhação a iniciativa partia do homem que, por meio de técnicas específicas e seguindo um ritual predeterminado, deduzia, de diferentes ocorrências, a resposta dos deuses para o caso em questão ${ }^{7}$. Mas a divindade podia, também, comunicar-se espontaneamente por meio de sonhos ou por meio de mensagens transmitidas a um intermediário, que a recebia em estado de transe. Nos textos conhecidos o intermediário desse tipo de comunicação com os deuses recebe, em geral, o título mahhûm ou muhhûm no caso de um homem e mahhîtum ou muhhutum no caso de uma mulher ${ }^{8}$ freqüentemente expresso pelo sumerograma $L U ́ . G U B . B A$ ou $S A L . G U B . B A^{9}$. O mahhûm/ muhhûm e a mahhûtum/muhhûtum formavam, provavelmente, uma classe de funcionários para cultos presentes nos templos de diferentes deuses ${ }^{10}$. Os textos do periodo babilônico antigo provenientes de Mari mencionam, também, como será exa- 
minado a seguir, casos em que a revelação divina, por meio de transe extático, é feita a pessoas leigas não ligadas ao grupo sacerdotal de um templo.

\section{O muhhûm/mahhûm nos testemunhos mais antigos}

A menção mais antiga ao mahhûm até agora conhecida aparece em uma carta da terceira Dinastia de Ur. Trata-se, provavelmente, de uma carta do rei Amar-Suena (c. 2045-2037 a.C.) a Sur-Lisina, governador da cidade de Umma ${ }^{11}$. A carta está escrita em acádico e determina que sejam fornecidos ao mahhûm da deusa Inanna da cidade de Girsu 60 GUR, cerca de 18 mil litros de cevada ${ }^{12}$. Em um contrato do tempo do rei Sabium (c. 1894-1881 a.C.) aparece um homem chamado Ahuwaqar, com o título profissional $L U . G U B . B A^{13}$ como testemunha do contrato ${ }^{14}$. Em um ritual de Larsa do período babilônico antigo, durante uma cerimônia em honra do deus solar Shamas, aparece, também, um $L U ́$.GUB.BA ${ }^{15}$. Dois outros documentos de Larsa, do ano $14 \mathrm{e}$ do ano 27 do rei Rim-Sin (c. 1822-1763 a.C.), falam de uma SAL LÚ.GUB.BA sha ND: "mulher de um mahhum do deus $N D^{\prime \prime 16}$. Em um tablete proveniente de Tell-ed-Der ${ }^{17}$, que contém um texto do periodo babilônico antigo com um recibo de rações de óleo distribuídas a diferentes pessoas, é anotado um litro dado a um $m u$-hu-um ${ }^{18}$. Pode-se citar aqui, ainda, uma carta do período babilônico antigo conservada no tablete VAT 7888 do Museu de Berlim ${ }^{19}$. O texto da carta apresenta algumas lacunas nas linhas 10 e 11 do anverso, por isso o contexto não é claro. No reverso do tablete lê-se a frase 10 $L \dot{U}$.GUB.BA li-it-ru-ni-kum: "que eles conduzam a ti" ${ }^{20}$. Pelo contexto não se pode concluir, com certeza, que o sumerograma $L U ́ . G U B . B A$ se refira, neste texto, ao sacerdote $m u h h u{ }^{21}$.

Entre os textos do periodo babilônico antigo encontrados em Susa, antiga capital elamita, pela expedição arqueológica de M. J. de Morgan aparecem duas interessantes alusões ao sacerdote muhhûm. A primeira está em uma pequena lista de animais destinados a diferentes templos ${ }^{22}$. Na linha 6 do reverso do tablete lê-se a menção de animais oferecidos por um tal Nurum, funcionário LÚ.GUB.BA DINGIR.RA: "muhhûm do deus" 23 . A segunda alusão encontra-se em uma lista, provavelmente de rações fornecidas a funcionários ${ }^{24}$, que registra 120 litros, certamente de cevada, dados a um tal Ribiia $m u-h u-u m^{25}$.

Todos os textos acima examinados mostram que a religião babilônica conhecia, pelo menos a partir de Ur III, uma classe de sacerdotes citados pelo nome de mahhûm ou muhhûm, que estavam de alguma maneira ligados ao culto. A ligação etimológica do título mahhîm/muhhûm com a raiz verbal mahûm, que indica "estar em um estado de transe", "tornar-se furioso" 26 , indica, sem dúvida, que a atuação destes sacerdotes no culto podia levá-los a um estado de transe extático ${ }^{27}$. 


\section{O muhhûm nos textos de Mari}

A melhor fonte de informação sobre o muhhû ${ }^{28}$, para o período babilônico antigo, acha-se, sem dúvida, nos textos cuneiformes que arqueólogos franceses encontraram nas escavações feitas em Tell Hariri. As escavações arqueológicas de Tell Hariri, uma localidade situada à margem direita do médio Eufrates, começaram em 1933 sob a direção de André Parrot. Os trabalhos de escavação neste Tell levaram os arqueólogos a descobrir o antigo reino de $\mathrm{Mari}^{29}$, que floresceu no século XVIII a.C. e foi destruído por Hammurabi pelo ano 1758 , no $35^{\circ}$ ano do seu reinado. A destruição levada a cabo pelos exércitos babilônicos foi tão profunda e completa que a cidade não foi nunca mais reconstruida e, assim, pôde-se encontrar, praticamente intacto, o arquivo do palácio real de Zimrilim (c. 1782-1759 a.C.), último rei de Mari, com seus cerca de 25000 tabletes cuneiformes, dos quais, pelo menos, 5000 são textos com cartas ao rei de Mari, escritas por governadores e outros funcionários das províncias vizinhas.

Nos textos de Mari o muhhûm e a muhhûtum são mencionados diversas vezes como intermediários de mensagens divinas ao rei. Pode-se citar aqui, como exemplo, o bem conservado texto da carta publicada em ARM III, 40:

Ao meu Senhor diz o seguinte, assim [falou] Kibri-Dagan, teu servo: Dagan e Ikrub-il vão bem, a cidade de Terqa e o distrito vão bem. Um outro assunto: No dia em que enviei este meu tablete a meu Senhor, veio um muhhûm de Dagan e disse: o deus me enviou. Apressa-te, escreve ao rei: Sejam oferecidos sacrifícios mortuários ao espirito de Iahdu-Lim. Isto me disse esse muhhûm e eu escrevi ao meu Senhor. Meu Senhor, queira fazer o que lhe parecer melhor.

Nesta carta o governador de Terqa escreve ao rei Zimrilim para comunicar-lhe uma mensagem do deus Dagan ao rei. A mensagem da divindade parece ter sido espontânea e o seu intermediário é um sacerdote muhhûm. Esse muhhûm legitima-se diante do funcionário do rei com a frase DINGIR ish-pu-ra-an-ni: "o deus me enviou". O conteúdo da mensagem é claramente de interesse religioso: Dagan exige que Zimrilim ofereça sacrifícios mortuários ${ }^{30}$ ao espírito ${ }^{31}$ de seu pai Iahdu-Lim.

Um outro exemplo que mostra bem a função do muhhûm e da muhhuitum na sociedade babilônica é representado pela carta enviada por uma mulher, chamada Addu-duri, ao rei Zimrilim, publicada em ARM 10,5. Addu-duri começa sua carta ao rei narrando dois sonhos que teve, que ela considera como um mau presságio. Em seguida relata:

Um outro assunto: uma muhhûtum levantou-se no templo de Annunitum e assim [falou]: Zimrilim, não deves partir para a expedição bélica. Permanece em Mari! Eu mesmo te responderei continuamente. Que meu Senhor não se descuide de proteger a sua pessoa. 
Nesta carta a sacerdotisa muhhîtum intervém no templo da deusa Annunitum e, em nome da divindade, desaconselha o rei de empreender uma determinada campanha bélica. A mensagem parece ter sido uma revelação espontânea da deusa: Não se tem notícia, na carta, de uma consulta do rei.

Em ARM III, 78, em uma carta de Kibri-Dagan ao rei Zimrilim, é relatada a intervenção de um muhhûm que se opõe à construção de uma determinada porta nova.

Um outro texto inédito de Mari (A 455) que contém uma carta de Lanasûm, governador de Tuttul, ao rei Zimrilim, citado por G. Dossin em seu artigo sobre o profetismo de Mari $^{32}$, relata a intervenção de um muhhûm diante da imagem do deus Dagan, transmitindo ao rei uma exigência desse deus relativa ao fornecimento de água para o templo.

No tablete publicado em ARM VI, 45 foi conservada uma carta de Bahdi-Lim, alto funcionário do palácio de Mari, ao rei Zimrilim. Em sua mensagem Bahdi-Lim fala ao rei a respeito do envio de uma mecha de cabelo e um pedaço da franja do manto de uma muhhûtum, que the fora entregue por Ahum, um sacerdote shangîm ${ }^{33}$. O cabelo e a franja do manto servem como identificação dessa muhhûtum que certamente deixara com o shangûm chamado Ahum uma mensagem divina.

Os textos de Mari apresentam, também, diversas mensagens divinas transmitidas ao rei por pessoas que não pertenciam ao colegiado religioso, que eram, pois, como hoje chamariamos, leigos. Este é, sem dúvida, um elemento muito importante para o estudo da natureza do movimento profético na Mesopotâmia.

No texto A 15 publicado em 1948 por G. Dossin ${ }^{34}$ encontra-se uma carta do funcionário real Itur-Asdu em que é apresentado a Zimrilim o relato de um sonho do funcionário Malik-Dagan, habitante de uma pequena localidade chamada Shakka. Nesse sonho o deus Dagan revela a Malik-Dagan que o motivo das dificuldades que o rei encontra em dominar as tribos nômades dos Benjaminitas está em sua falta de confiança no deus Dagan. 0 deus queixa-se de que o rei não o mantém informado de todos os seus passos. A mensagem divina para o rei é clara:

Agora vai! Eu te envio! A Zimrilim diz o seguinte: Envia-me teus mensageiros e informa-me detalhadamente! Eu farei os xeques dos Benjaministas pulular em um cesto de pescador e os colocarei à tua disposição.

Nesta mensagem, o deus Dagan exige que o rei tenha mais consideração e maior generosidade para com o seu templo em Terqa.

Em ARM XIII, 112 o funcionário Kibri-Dagan relata ao rei Zimrilim o sonho de um suharum, um jovem servidor, em que uma divindade, provavelmente Dagan, transmite ao rei uma determinada mensagem. O tablete apresenta uma lacuna no fim do lado anverso que causou a perda de várias linhas. $\mathrm{O}$ reverso, porém, está relativamente bem conservado e a mensagem divina apresenta a proibição da reconstrução de uma determinada casa. A ameaça do deus é clara: "Não reconstruireis essa casa! Se vós a recons- 
truirdes, eu a farei cair no rio!" O texto da carta não fornece maiores informações sobre a natureza dessa casa e nem sobre os motivos da proibição divina.

Já a mensagem divina recebida por um awilum, um cidadão, provavelmente de Terqa, relatada ao rei na carta de Kibri-Dagan publicada em ARM XIII, 114 não é compreensível devido ao estado lacunar do tablete.

Na carta de Kibri-Dagan a Zimrilim, publicada em ARM XIII, 114, a mensagem do deus Dagan, transmitida por meio da esposa de um awilum, é de conteúdo claramente político. A mulher intermediária da mensagem divina legitima-se pela fórmula dagan-ish-pu-ra-an-ni: "Dagan enviou-me". A mensagem refere-se a Hammurabi, rei da Babilônia, em relação ao qual Zimrilim não se devia inquietar. Infelizmente o reverso do tablete está ilegível, de maneira que não se pode saber quais foram os fatos relativos a Hammurabi, cujo conhecimento devia tranquilizar o rei de Mari.

Uma outra mensagem divina relativa à política internacional foi conservada na carta da rainha de Mari, Shibtu, a seu esposo Zimrilim, publicada em ARM X, 6. O intermediário da divindade foi um homem chamado Ili-haznaya, cujo titulo profissional, segundo a reconstrução incerta do texto feita por Dossin, seria $L U$ Us-si-in-nu sha an-nu-ni-tim: "assinnu da deusa Annunitum",35. No texto do reverso do tablete, Ilihaznaya, interrogado pela rainha, responde em relação a Hammurabi:

Esse homem planeja muitas coisas contra este país. Ele não terá êxito. Meu Senhor verá o que deus fará a esse homem. Tu o vencerás e te estabelecerás sobre ele. Seus dias estão contados; ele não viverá mais. O meu Senhor saiba disso.

A rainha relata, ainda, a Zimrilim que, antes de receber a mensagem de Ili-haznaya, ela mesma, durante cinco dias, fizera muitas consultas e todas as respostas obtidas estavam de acordo com a mensagem de Ili-haznaya. Não se conhecem, hoje, as circunstâncias exatas a que esta mensagem se referia. $\mathrm{O}$ curso da história, contudo, não confirmou a predição da deusa Annunitum, já que Zimrilim foi derrotado e o reino de Mari destruído por Hammurabi no $35^{\circ}$ ano do seu reinado ${ }^{36}$.

Em uma outra carta da rainha Shibtu a seu esposo Zimrilim, publicada em ARM X, 10, é relatada a visão ${ }^{37}$ que uma mulher, chamada Kakka-lidi, teve no templo do deus Itur-Mer ${ }^{38}$. Nesta revelação divina ela viu dois grandes barcos que bloqueavam o rio; o rei e os soldados redûm estavam embarcados nesses barcos. Os redûm que estavam no barco da direita gritavam para os da esquerda: "A realeza, o cetro e o trono estão firmes! O país superior e o país inferior estão entregues a Zimrilim". Neste momento os redîm gritavam em coro: "estão entregues a Zimrilim". Esta mensagem divina, recebida por intermédio de uma pessoa leiga ao serviço do templo, era para o rei, sem dúvida, um encorajamento e um incentivo para os momentos dificeis que Zimrilim teve que atravessar para reconquistar o trono de seu pai.

Duas outras cartas da rainha Shibtu a Zimrilim, publicadas em ARM X, 7 e 8, são muito importantes, neste contexto, por nos mostrarem como os dois "profetas" receberam a mensagem divina. 
Em ARM X, 7 lê-se:

Ao meu Senhor diz: assim [falou] Shibtu, tua serva: O palácio vai bem. No templo de Annunitum, no terceiro dia, Shelibum caiu em êxtase ${ }^{39}$. Assim [disse] Annunitum: Zimrilim! Por meio de uma rebelião querem colocar-te à prova. Cuida de tua pessoa! Teus servos fiéis, de quem tu gostas, coloca-os ao teu redor! Coloca-os a postos para que eles te guardem. Não deves, jamais, andar sozinho! Os homens que te colocaram à prova, eu os entregarei em tuas mãos! Agora, pois, fiz chegar à tua presença o cabelo e a franja do manto do assinn $u^{40}$.

Nesta carta a mensagem da deusa, relatada ao rei, foi recebida por intermédio do assinnu Shelibum; trata-se, pois, de um funcionário dos cultos no templo de Annunitum. A comunicação da divindade foi recebida por Shelibum em um estado de transe extático, descrito pela forma verbal $\mathrm{N}$ da raiz mahûm ${ }^{41}$. O teor da mensagem é, claramente, de cunho político. A rainha, por meio desta mensagem da deusa Annunitum, quer precaver o rei contra uma rebelião que se estava armando contra ele.

Na segunda carta, ARM X, 8, a rainha Shibtu comunica ao rei uma outra mensagem da deusa Annunitum recebida por uma mulher chamada Ahatum, filha de MalikDagan.

Ao meu Senhor diz: assim [falou] Shibtu: No templo de Annunitum, no meio da cidade, Ahatum, uma jovem filha de Malik-Dagan, caiu em êxtase e disse o seguinte: Zimrilim, mesmo que tu me desprezes, eu te amarei. Teus inimigos, eu [os] entregarei em tuas mãos. Quanto àqueles que me roubam, eu os capturarei e os reunirei para o massacre de Belet-ekallim! No dia seguinte, Ahum, o [sacerdote] shangum, trouxe-me esta mensagem, a mecha de cabelos e a franja do manto, e eu escrevi a meu Senhor. Selei a mecha de cabelos e a franja do manto e enviei, então, ao meu Senhor.

Nesta carta, a mensagem da deusa Annunitum é comunicada por intermédio de uma jovem chamada Ahatum, apresentada como filha de Malik-Dagan. Trata-se, pois, de alguém que não parece pertencer ao corpo de funcionários do templo da deusa. $\mathrm{O}$ estado psicológico do intermediário ao receber a mensagem é, porém, o mesmo referido no texto anterior: o transe extático expresso pela raiz verbal mahûm. $\mathrm{O}$ conteúdo da mensagem com a proclamação do amor gratuito da deusa em relação ao rei Zimrilim nos faz lembrar alguns textos proféticos do Antigo Testamento ${ }^{42}$.

Como último exemplo ${ }^{43}$ dos textos de Mari vale a pena examinar a carta de uma mulher chamada Inibsina ao rei Zimrilim, publicada em ARM X, 80.

A minha estrela diz: assim [falou] Inibsina: Antes o assinnu Shelibum entregara-me um oráculo e eu te escrevi. Agora veio uma qabbatum ${ }^{44}$ de Dagan de Terqa e falou nos seguintes termos: Os sinais de amizade do homem de Eshnunna são vexação. Debaixo da palha a água corre, mas com a rede, que eu farei, eu o reunirei. Destruirei 
sua cidade e sua propriedade, que existe há muito tempo, eu saquearei totalmente! Eis o que ela disse. Agora cuida de ti. Não entres no interior da cidade sem um oráculo. Eu ouvi dizer o seguinte: ele teme continuamente por sua pessoa. Não temas, continuamente, por tua pessoa.

Esta nova mensagem do deus Dagan é dirigida ao rei Zimrilim por intermédio de uma sacerdotisa do templo de Dagan em Terqa da classe das qabbatu. Seu conteúdo trata de política internacional. O rei Zimrilim é advertido pela divindade a não se fiar nas belas palavras do $L U$ esh-nun-na": "homem de Eshnunna". Trata-se, provavelmente, do rei de Eshnunna, que tentava, em sua luta contra Hammurabi, obter o apoio de Mari. A posição do clero do templo de Dagan em Terqa parece ter sido, nesta ocasião, favorável a Hammurabi e por isso tenta por meio do oráculo divino impedir toda e qualquer aliança com o reino de Eshnunna.

\section{O período cassita}

Em 1594 a.C., com a derrota de Samsuditana (1625-1595 a.C.), último rei da dinastia de Hammurabi, diante das tropas hititas e de seus aliados hurritas e cassitas, o núcleo daquilo que constitui o reino de Hammurabi caiu nas mãos dos cassitas, que dominaram a Babilônia até 1157 a.C. aproximadamente ${ }^{45}$. Este periodo é conhecido entre os assiriólogos como o período babilônico médio: trata-se de um período bastante obscuro da história da Babilônia, já que os textos cuneiformes provenientes desta época são, em comparação com os de outras épocas, significativamente menos abundantes. Não é, pois, de estranhar que nos textos do periodo cassita não se encontrem testemunhos da presença do mahhûm. A única menção que conheço, entre os textos desta época, é proveniente de uma região periférica. Trata-se de um texto de caráter sapiencial, do tipo "justo sofredor", encontrado em Ras-Shamra, uma localidade da Síria, onde nos sécs. XIV-XIII a.C. floresceu o reino de Ugarit ${ }^{46}$. Nesse texto lê-se na linha 11: ahhua kima mahle damishunu ramku: "meus irmãos estão lavados em seu sangue como os mahhh",47. Esta afirmação parece referir-se a ferimentos e incisões que os mahhî, durante o estado de transe extático faziam em seus próprios corpos ${ }^{48}$.

\section{O mahhû nos textos neo-assírios}

No período neo-assírio, principalmente nos textos dos arquivos de Assarhaddon (680-669 a.C.) e de Assurbanipal (669-630 a.C.) encontram-se, novamente, diversas alusões a oráculos transmitidos pelo mahhû. Em uma inscrição do rei Assahaddon lê-se

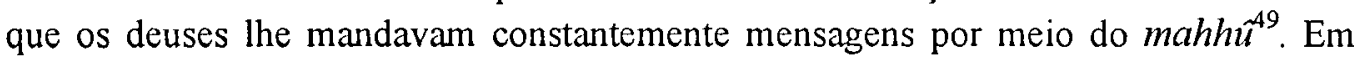


uma outra inscrição, Assarhaddon proclama que os grandes deuses e deusas lhe enviam constantemente shi-pir mah-he-e: "mensagem dos mahhî" e mensagens divinas ${ }^{50}$. Nesta inscrição proveniente de Nínive nota-se claramente a preocupação de Assarhaddon em legitimar por meio das mensagens e respostas dos deuses o seu direito ao trono, já que não era o filho primogênito de Senaqueribe. Trata-se, pois, de uma espécie de legitimação carismática.

No tratado de vassalagem imposto por Assarhaddon a Ramataia pode-se perceber, claramente, o respeito e, ao mesmo tempo, o temor que os soberanos sargônidas tinham às palavras dos profetas extáticos e de outros intermediários de mensagens divinas, certamente pela força política que eles podiam representar. De fato, no tratado de vassalagem há uma cláusula pela qual Ramataia se compromete a relatar a Assurbanipal todo e qualquer rumor, boato ou notícia sobre a pessoa do príncipe herdeiro, quer esta novidade venha de um inimigo, de um amigo, de um membro da familia real, de um mahhû ou de uma outra figura profética ${ }^{51}$.

As inscrições de Assurbanipal testemunham, igualmente, a presença do mahhû na vida pública da Assíria. Como seu pai, assim também Assurbanipal se gloria de receber, constantemente, em sonhos e por meio de oráculos do mahhû, mensagens da deusa $\mathrm{Ishtar}^{52}$. Na inscrição do cilindro B dos anais, Assurbanipal celebra a sua vitória sobre o rei elamita Tammaritu II com as palavras: "Por ordem de Assur e de Marduk, os grandes deuses, meus senhores, que me apóiam, por meio de bons augúrios, por meio de sonhos, de egerri $\hat{i}^{53}$ e por meio de mensagens dos mahhî inflingi-lhe uma derrota em Tulliz" ${ }^{\text {,54 }}$. Em uma outra inscrição conservada no tablete cuneiforme de Nínive K 2638, que se encontra hoje no British Museum, Assurbanipal fala de sonhos e oráculos dos mahhû que a deusa Nanâ the enviou por ocasião de uma incursão bélica do rei elamita Kudur-Nanhunte contra a Babilônia ${ }^{55}$.

Em um texto litúrgico do período neo-assírio ${ }^{56}$ lê-se esta interessante afirmação sobre o mahhî: "o mahhû, que caminha diante de Belet-Babili, é um mensageiro, ele chora em seu peito" 57 . O título $L U ́$ mu-pa-si-ru: "mensageiro" sem dúvida, uma alusão à função do muhhû de ser o intermediário, o porta-voz da divindade durante a ação litúrgica.

No tablete de Assur VAT $8916^{59}$, que é, provavelmente, um texto ritual do culto de Tammuz ${ }^{60}$, lê-se: "[...] deves colocar alimentos para o zabbu e a zabbatu" ${ }^{61}$, para o mahhî e a mahhûtu". O texto mostra, pois, a presença desses tipos de "profetas" extáticos, certamente membros de uma classe de funcionários ligados aos cultos, durante uma liturgia.

\section{O mahhû nos textos mais recentes}

Em um texto litúrgico de Uruk, do tipo ritual, proveniente provavelmente do período neo-babilônico, é mencionada uma participação do mahhû no culto da deusa 
Belit-sha-Uruk com as palavras: "[...] três vezes anda o mahhû com isto[?] em volta, ele dá água para as mãos[...]"62.

Em um outro texto da época recente em que o mahhû é mencionado, o texto conservado no tablete $\mathrm{K} 8204^{63}$, o contexto é muito obscuro e o conteúdo do texto muito dificil de ser interpretado. A frase al-la-pit-ki-ma mah-hi-e pode ser traduzida, aproximadamente, por "fui possuído como o mahhû"; uma possível alusão ao estado de transe em que os mahhî atuavam.

\section{O mahhû nos textos de presságios}

As diversas séries de presságios conservadas em tabletes cuneiformes de épocas mais recentes formam um interessante grupo de textos religiosos babilônicos, que nos oferecem uma certa possibilidade de conhecer como eram, em geral, avaliados os mahhû nesta época. Assim, na série conhecida como "shumma âlu ina mele shakin" lê-se: "Se em uma cidade os mahhû são abundantes: desgraça para a cidade" 64 . "Se em uma cidade as mahhûtu são abundantes: desgraça para a cidade" Presságios como estes mostram, certamente, que na época de sua composição os mahhû e as mahhûtu não pareciam gozar de boa reputação. Sua presença em grande número, em uma cidade, era interpretada pelo exorcista como sinal de desgraça para essa cidade. ${ }^{66}$

Na série "enuma ana bit marsil" publicada por R. Labat ${ }^{67}$ encontra-se o seguinte prognóstico: "Quando o exorcista vai à casa de um doente, se ele viu um mahhî, esse doente[...] $]^{\prime 68}$ Infelizmente o tablete apresente uma lacuna exatamente no lugar onde estaria a apódose do presságio, com a interpretação da ocorrência observada na prótase em relação ao doente. Mas, feita uma comparação com o presságio anterior, pode-se sugerir tratar-se, aqui também, de um mau presságio para o doente.

As listas lexicográficas mais recentes ${ }^{69}$ costumam equiparar ao mahhîm vários outros tipos extáticos como o eshsheb $\hat{u}^{70}$, o parrî $^{71}$, o ushshurum ${ }^{72}$, o zabbu ${ }^{73}$. Todos esses tipos distinguiam-se, certamente, das outras pessoas por sua aparência externa estranha, por seu modo de se apresentar e de atuar em público um tanto quanto frenético que se assemelhava bastante com o estado de transe extático do mahhû e levava o povo a considerá-los, também, como "possuídos" pela divindade.

\section{Conclusões}

Os textos acima examinados oferecem, sem dúvida, alguns elementos valiosos que podem contribuir para uma melhor compreensão da natureza e do significado da adivinhação "inspirada" na religião babilônica. Existiram, certamente, na Babilônia 
várias figuras de "profetas extáticos"74 . Neste artigo, contudo, a atenção foi concentrada na figura do muhhûm/mahhûm, já que ele aparece nos textos babilônicos com muito maior freqüência. Mereceram, também, uma atenção especial as mensagens proféticas recebidas por leigos por intermédio de transe extático.

$\mathrm{O}$ testemunho mais antigo da presença do muhhûm/mahhûm no culto parece ser representado, até hoje, pela carta do rei Amar-Suena (c. 2045 - 2037 a.C.) a Sur-Lisina, governador da cidade de Umma, com a ordem de fornecer ao mahhû da deusa Inanna de Girsu 60 GUR de cevada. Durante o período babilônico antigo o muhhûm/mahhûm é geralmente mencionado nos textos pelo sumerograma $L U ́$.GUB.BA, cujo significado não é claro ${ }^{75}$. O título acádico é escrito silabicamente em Mari e um texto de Tell ed-Der na forma muhhûm${ }^{76}$. Esta forma foi explicada, geralmente, como uma variante dialetal de mahhûm ${ }^{77}$. Mas D.O. Edzard mostra que a forma mahhûm/mahhûtum aparece apenas a partir de 1500 a.C. ${ }^{78}$. Nesta linha pode-se, talvez, concluir que a forma muhhûm/muhhûtum seja a mais antiga. O título muhhûm/mahhûm deve ser etimologicamente, sem dúvida, ligado à raiz verbal acádica mahû que significa "estar fora de si", "entrar em um estado de transe" que a classe de pessoas designadas como muhhûm-mahhûm costumava agir em estado de transe extático. O ritual de Larsa examinado acima, e outros textos do período babilônico antigo, mostram uma ligação do muhhûm/mahhûm com o culto. O muhhûm/mahhûm parece, pois, ter formado uma classe de "profetas" profissionais ligados aos funcionários do culto nos templos de diversos deuses.

Os textos do período babilônico antigo, provenientes do antigo reino de Mari, são, sem dúvida, pela quantidade de material e pela qualidade de informações que fornecem, aqueles que mais contribuem para uma melhor compreensão e uma formulação mais completa do perfil do muhhûm/mahhûm.

Entre os textos de Mari existem algumas cartas enviadas ao rei Zimrilim pela rainha Shibtu e por outros funcionários do palácio que comunicam ao rei mensagens dos deuses transmitidas por intermédio dos "profetas" profissionais muhhûm e muhhûtum. Estas mensagens são comunicadas ao muhhûm ou à muhhûtum em visões ou audições recebidas em um estado psicológico de transe extático. Não é descrita a maneira como o muhhûm atingia o estado de transe extático. A autoridade da mensagem transmitida como divina é legitimada pela fórmula ilum ishpuranni: "o deus me enviou", muito semelhante à célebre fórmula do legado: "Assim falou Yahweh" que legitimava os profetas do Antigo Testamento. O conteúdo da mensagem era de natureza cultual, de natureza política ou de interesse pessoal do rei. Mas a natureza da mensagem é aqui, certamente, determinada pelo fato de todo material estudado originar-se dos arquivos do palácio real.

Os arquivos de Mari fornecem, também, um outro elemento de grande importância para o estudo do fenômeno profético de Mari. Nestes textos, ao lado do "profeta" profissional, aparecem pessoas que não pertenciam à classe sacerdotal, leigos, portanto, ao serviço dos templos, e que transmitem ao rei mensagens recebidas dos deuses. Estas 
mensagens são recebidas ou em sonhos ou em um estado de transe extático descrito em dois textos ${ }^{80}$ pelo verbo mahû. O conteúdo das mensagens dos "profetas" leigos é semelhante ao dos oráculos do muhhûm: temas relacionados com o interesse do templo ou com a política internacional do rei de Mari. Aqui, também, a natureza do material determinou, certamente, a temática das mensagens divinas.

Nos textos de Mari, além do muhhûm, da muhhûtum e de leigos são mencionados, ainda, o funcionário religioso assinu $^{81}$ e a profetiza qabbatum ${ }^{82}$ como intermediários de mensagens divinas.

Um texto sapiencial do tipo "justo sofredor" encontrado nas escavações de RasShamra apresenta uma interessante afirmação que ilumina um aspecto do procedimento do mahhûm durante sua manifestação profético-cultual. Neste texto o "justo-sofredor" falando de seus irmãos declara: ahhua kima mahhê damishunu ramku": "meus irmãos estão lavados em seu sangue como os mahhî". Trata-se aqui, provavelmente, de uma alusão à maneira como os mahhû se comportavam durante o transe extático, quando, fora de si, causavam ferimentos e incisões em seus próprios corpos ${ }^{84}$.

No período neo-assirio os reis da dinastia sargônida, principalmente Assarhaddon (680-669 a.C.) e Assurbanipal (669-630), apelam, diversas vezes, para os oráculos dos mahhû para justificar e legitimar suas pretensões e seu agir político. Isto mostra, sem dúvida, a força moral destes ditos proféticos e o respeito que gozavam entre o povo. Eles eram considerados, juntamente com os sonhos e outros tipos de oráculos, manifestações da vontade dos deuses. Aliás, parece ter sido o medo que os reis tinham da autoridade de tais oráculos junto ao povo, que levou Assarhaddon a incluir no tratado de vassalagem selado com Ramataia a cláusula que previa a obrigação deste de comunicar ao príncipe-herdeiro Assurbanipal todo e qualquer oráculo ou dito profético a seu respeito. Por ocasião de empreendimentos bélicos importantes, Assurbanipal teve também, constantemente, a preocupação de conhecer a vontade dos deuses em relação àquela campanha militar que o mahhî lhe anunciava.

Em um texto litúrgico do período neo-assírio o mahhû recebe o epíteto $L U ́$ mupa-si-ru : "mensageiro", que nos informa sobre uma das funções do mahhû no culto: ele era o mensageiro dos deuses. Nesse mesmo texto é dito, ainda, que o mahhû chora no peito da divindade ${ }^{86}$. Esta segunda afirmação permite-nos, provavelmente, concluir que uma outra função importante do mahhû era a de ser o intercessor do povo junto à divindade.

A presença do mahhû no culto babilônico é testemunhada não só no texto litúrgico acima citado, mas também em um outro texto litúrgico, provavelmente um texto ritual do culto de Tammuz ${ }^{87}$. Este ritual determina que durante a ação litúrgica sejam depositadas provisões para os "profetas" de culto zabbu, zabbatu, mahhû e mahhûtu.

A atuação do mahhû no culto é também confirmada para o período neo-babilônico (c. 609-539 a.C.) em um texto litúrgico proveniente de Uruk ${ }^{88}$.

A presença do muhhûm/mahhûm na religião e no culto da Babilônia e da Assíria é, pois, uma constante desde o período babilônico antigo. Infelizmente não existem nos 
textos, hoje conhecidos, elementos suficientes para determinar com certeza, todas as funções e atribuições do muhhûm/mahhûm no culto babilônico.

Os testemunhos hauridos das diversas séries de presságios e prognósticos compostas em épocas mais recentes da história da religião babilônica parecem mostrar uma tendência de decadência e um crescente descrédito do povo em relação à figura do muhhûm e da mahhûtum. A presença numerosa de mahhû ou de mahhûtum em uma cidade é interpretada como um sinal de desgraça para essa cidade ${ }^{89}$. A mesma tendência negativa parece conservada nas listas lexicográficas mais recentes, em que tipos mais ou menos estranhos e dúbios da religião babilônicas são explicados pelo termo $\operatorname{mahh} \hat{u}^{90}$.

Os textos cuneiformes, hoje conhecidos, informam-nos, pois, que, além da adivinhação dedutiva tão abundantemente testemunhada nos textos babilônicos, havia um outro tipo de contato com a divindade: a adivinhação "inspirada". Esses textos permitem, além disso, iluminar alguns aspectos da natureza dessa adivinhação e da maneira como os deuses nela se comunicavam com os homens. Mas continuam, ainda, no ar muitas perguntas e muitas dúvidas sobre a natureza desse tipo de adivinhação. Esperemos que outros textos cuneiformes trazidos à luz futuramente pela arqueologia possam responder a essas questões e nos permitam um conhecimento mais exato desse fenômeno tão importante da religião babilônica.

\section{Notas}

1- Ver por exemplo: Bottéro, in: Vernant, J.-P., 1974, p. 70-201.

2- Ver Oppenheim, 1976, p.206-27.

3- Uma coleção de textos do período babilônico antigo para uso do barû, o sacerdote encarregado da interpretação dos sinais encontrados no figado das vítimas, foi publicado por Goetze, YOS 10.

4- Ver Weidner, 1915, v.1; Meissner, 1925, v.2, p. 247-260; Sachs, A.J. e Hunger, H., 1988, v.1.

5- Ver Oppenheim, 1976, p. 207.

6- Ver Pettinato, 1966.

7- Ver Bottéro, 1974, p. 99-127; Starr, 1973.

8- Ver The Assyrian Dictionary, v.10: M 1. The Oriental Institute, Chicago, 1977, p.90; Soden, W. von, Akkadisches Handworterbuch, v. 2, Otto Harrassowitz, Wiesbaden 1972, p. 582.

9- No período babilônico mais recente, a lista lexicográfica lú-sa cita outros sumerogramas correspondentes a mahhû como LÚ.NÍ.SU.UB, LÚ.AL.E.DE e LÚ.AN.NÉ.BA.TU (Ver Civil, M. Materials for the Sumerian Lexikon, v.12, Pontificium Institutum Biblicum, Roma, 1969, n. 116,118,147.)

10- Ver Renger, 1969, p. 218-23. Uma opinião contrária é defendida por J. Bottéro, 1974, p. 91. 11- Esta carta foi publicada por Sollberger, E., 1966, p. 90, n. 369. Sobre a cidade de Umma ver Edzard e Farber, 1974, v. 2, p. 204. Situada onde hoje se encontra a localidade Tell Goha. 12- O texto acádico da carta pode ser traduzido: "Assim o rei, a Sur-Lisina diz: dá 60 GUR de cevada ao muhhûm de Innana de Girsu". 
13- Como foi visto acima o sumerograma $L U ́ . G U B . B A$ é usualmente empregado para indicar o mahhûm.

14- Ver Thureau-Dangin, F. TCL 1, n. 57, 20-21.

15- Ver Kingsbury, E.C., 1963, p. 10-89.

16- Cfr. Jean, Ch.-F. TCL X, 39, 11;69, 4.

17- Sobre a localização de Tell ed-Der ver Edzard, D.O., 1974, p.13 seq.

18- Ver Edzard, D.O., 1970, p.134, n. 111 Rs 2.

19- A cópia deste tablete foi publicada em Schroeder, O., 1917, n. 144.

20- Esta frase encontra-se no reverso do tablete, linha 18.

21- O sumerograma $L \dot{U} . G U B . B A$ aparece, aqui, em um contexto em que se fala do envio de soldados redûm.

22- Este texto foi publicado com cópia cuneiforme do tablete e transcrição em Scheil, 1908, p. 25, n. 7,6 .

23- Nas linhas 9 e 10 deste mesmo tablete fala-se de um Duldulum que recebe o título LÚ.GUB.BA DINGIR.RA.

24- A cópia cuneiforme deste texto foi publicada por Dossin, 1927, p. 51, n. 171,14. Ver a interpretação de Scheil, V. em Revue d'Assyriologie 14, Paris, 1917, p. 92 seq.

25- O texto não é claro. Provavelmente, trata-se de um nome próprio Ri-bi-ia e do título $m u-h u-u m$.

26- The assyrian Dictionary, M.1, p.115, traduz a raiz mahû por "to become frenzied; to go into a trance". Soden, em Akkadisches Handwörterbuch, vol. 2, p. 586, traduz para a forma N "ins Rasen kommen".

27- Ver Bottéro, J., 1974, p. 93 seq.

28- A forma muhhûm foi publicada em artigo de Soden em Die Welt des Orients 1, Göttingen, 1947-1952, p.400, como uma variante dialetal derivada de mahhûm. Mas Edzard julga que mahhûm aparece apenas a partir de 1500 a.C.; enquanto que muhhûm é a forma mais antiga. Ver Edzard, D. O., 1974, p.134.

29- Para uma rápida informação sobre os trabalhos arqueológicos e descobertas feitas em Mari ver: Parrot, 1945 e 1974. Os resultados dos trabalhos arqueológicos de Mari estão publicados nos 5 volumes editados por Parrot sob o título: Mission Archéologique de Mari, Paris: Librairie Orientaliste Paul Geuthner, 1958-1967.

30- Sobre o significado do termo acádico kishpum ver The Assyrian Dictionary, K, p. 425, que traduz por "funerary offering" e Soden, W. von, Akkadisches Handwörterbuch, v. 1, p. 487 onde o termo é traduzido por Totenopfer.

31- O termo acádico atemmum é traduzido por W. von Soden em Akkadisches Handworterbuch, p.263, v.1, por Totengeist. Em The Assyrian Dictionary, E, p. 397, por spirit of the dead.

32- Ver Dossin, 1966, p. 79 seq.

33- Ver Renger, J., 1969, p. 104 seq.

34- Revue d'Assyriologie 42, Paris, 1948, p. 125-34.

35- A tradução "eunuco" de Dossin não parece ser nem a única, -nem a melhor. The Assyrian Dictionary, A 2, p.341, traduz o termo de maneira mais vaga como a member of the cultic personnel of Ishtar. W. von Soden em Akkadisches Handwörterbuch, v.1, p.75, traduz o termo por etwa Buhlknabe (im Kult). De fato Annunitum era um dos nomes da deusa Ishtar. Ver Haussig, 1965, p. 42, v. 1.

36- Na fórmula que determinava o ano 35 de Hammurabi lê-se: "Por ordem de Anu e de Enlil ele destruiu os muros de Mari e os muros de Malgu”. Ver Ungnad, "Datenlisten". In: Ebeling, 
E. e Meissner, B., 1938, p. 181, v. 2. A destruição do reino de Mari aconteceu pelo ano 1759 a.C. Para um relato sucinto da história da Babilônia na época de Hammurabi ver Bouzon, 1987, p. 15 seq.

37-É usada no texto acádico a forma verbal $i-m u-u r$, um pretérito $G, 3^{\mathrm{a}}$ pessoa singular, da raiz verbal amãrum = "ver".

38- Sobre a divindade Itū-Mēr ver Kupper, J.R. art. Itū-Mēr. In: Edzard, D.O., 1, p. 222, v. 5. Era um dos deuses protetores de Mari.

39- A forma verbal aqui usada, im-ma-hu, é um pretérito $\mathrm{N}$ da raiz verbal mahùm que como foi dito acima indica um estado de transe, um estar fora de si ou furioso.

40- Sobre a figura do funcionário de cultos assinnu ver o que foi dito acima.

41- Sobre o significado da forma verbal N em acádico ver Soden, 1952, 90, p. 117 seq.

42- Compare por exemplo: Os 11,1.

43- Outros exemplos são ARM X,81 com a resposta de uma apiltum. O tablete está, porém em mau estado de conservação e assim não se pode conhecer o conteúdo da mensagem.

44- Ver The Assyrian Dictionary, Q, p. 2; Soden, 1933, p. 886, v. 2. Ver também Renger, art.cit., p.219. O título qabbatum parece ter indicado uma classe de profetisas dos cultos.

45- para a história deste período ver Brinkman, 1976, v. 1: A catalogue of cuneiform sources pertaining to specific monarchs of the Kassite Dynasty. Ver também Fischer, Weltgeschichte, p. $9-70$, v. 3 .

46- Sobre o reino de Ugarit e sobre as escavações em Ras Shamra ver Schaeffer, 1939, t. 3: Ugaritica. Études relatives aux découvertes de Ras Shamra.

47-Este texto foi publicado em Nougayrol, Laroche, et al., 1968, p. 267, linha 11.

48- Compare relatos paralelos do AT com 1 Sam 19, 21-24; 1 Rs 18, 28, Zac 13, 2-6.

49- Ver Borger, 1956, p. 2, 2, A II, 12-13; Thompson, 1931, p. 13, col. II, 6.

50- Ver Borger, 1931, p. 45, 27, II, 6-7.

51- Ver Wiseman, 1958, p. 38.

52- Ver Thompson, 1931, p. 31, P1 14, col. 2,16-17.

53- O termo acádico egerrû é interpretado por Soden, W.von, em Akkadisches Handwörterbuch, como uma espécie de "oráculo". The Assyrian Dictionary, E, p. 43, registra, também, o significado an oracular utterance of uncertain nature.

54- Ver Streck, M. Assurbanipal und die letzten assyrischen Könige bis zum Untergange Niniveh's, Leipzig. J.C. Hinrich,1916, p. 120, v. 2, Cilindro B, col. V, 93-96.

55- O texto do tablete K 2638 foi publicado em transcrição e tradução por Bauer, 1933, p. 61 seq.

56- Este texto foi publicado por Ebeling, 1919, n. 143. W. von Soden transcreveu, traduziu e comentou este texto em Zeitschrift fur Assyriologie 51, Berlim, 1955, p. 130-66.

57- Ver Soden, W. von, art. cit., p. 134.

58- O termo acádico mubassiru ou mupassiru, uma forma participial da raiz verbal bussuru indica o mensageiro, aquele que transmite uma mensagem. Cf. Soden, 1972, p.665, The Assyrian Dictionary, M 2, p.158.

59- Este texto foi publicado por Ebeling, 1953. Uma duplicata deste texto encontra-se no tablete K 2001 da biblioteca de Assurbanipal em Nínive, publicado por Craig, 1895, n. 16.

60- Para a interpretação deste texto ver Ebeling, 1931, p. 47 seq.

61- O sacerdote zabbum e a sacerdotisa zabbutum parecem ter sido um tipo de "profeta" extático semelhante ao muhhûm/mahhûm. Ver Renger, 1969, p. 218 seq.; The Assyrian Dictionary, p. 7 seq.

62- A cópia do texto do tablete VAT 14524 foi publicada por Falkenstein, 1931, p. 20.

63- O texto foi publicado no fim do século passado por Strong, 1895, p. 138 seq.

64- A cópia dos tabletes de Nínive que contêm o texto cuneiforme desta série foi publicada por 
Gadd, 1925-1927, v. 38-40. Estes textos foram transcritos e traduzidos em alemão em artigo de Nötscher, Orientalia 31, Roma, 1928, p. 1-78.

65- Ver Gadd, 1925-1927, v. 38, Plate 4,81; Nötscher, F., art. cit., p. 49.

66- Ver Gadd, 1925-1927, 38, Plate 4,82; Nötscher, F., art. cit., p. 49.

67- Ver Labat, 1951.

68- Ver Labat, 1951, p. 4,30.

69- Ver Soden, 1933, p.3, 1,VI, 41-44 onde são registrados os seguintes sinônimos: esh-she-bu-u =mah-hu-u

pa-ru-u $=m a h-h u-u$

$u$ sh-shu-ru $=m a h-h u-u$

$z a-a b-b u=m a h-h u-u$

70- The Assyrian Dictionary, vol. E, p. 371, registra o termo eshshebû (fem. eshshebûtu) como an ecstatic with evil magical powers e acrescenta o comentário The Sum designation of the ashsheb $\hat{u}$, an-ni-ba-tu, one who has been entered by a divine power', shows that the term refers to an ecstatic, as is also indicated by the term mahhu[...] which is used in Hg to explain the word eshshebû that has become obsolete.

71- W. von Soden registra em seu Akkadisches Handwörterbuch, p. 834, v. 2, o termo parrû com o significado Buhlknabe, Kinäde. Trata-se, provavelmente de alguém que atuava nos cultos de fertilidade.

72- O significado do termo ushshuru/wushshuru neste contexto não é claro. W. von Soden en seu Akkadisches Handwörterbuch, p. 1498, v. 3, relaciona o termo com os cabelos longos e neste caso indicaria aproximadamente "cabelos longos caídos sobre os ombros". A equiparação ushshuru = mahhû indicaria que os mahhû usavam cabelos longos caídos sobre os ombros.

73- O zabbu e a zabbatu formavam uma classe de sacerdotes que atuavam como profetas em cultos extáticos. Ver Renger, 1969, p. 219.

74- Ver Renger, 1969, p. 219.

75- A interpretação é feita em geral a partir da identificação $G U B=$ izuzzum com o significado "aquele que está de pé".

76- Ver Edzard, op. cit., p. 134, $\mathrm{n}^{\circ} 111$, Rs 2.

77- Ver Soden, 1947-1952, p. 400.

78- Ver Edzard, op.cit., p. 143, n. 2.

79- Ver The Assyrian Dictionary, vol. M I p.

80- Ver ARM X,7 e ARM X,8.

81- Ver ARM X,7 - compare ARM X,80.

82- Ver ARM X,80.

83- Ver Ugaritica V, p. 267, linha 11.

84- Compare 1 Sam 18, 28: Zac 13,2-6.

85- Ver Soden, W. von, art. cit., p. 134.

86- Ver ibidem.

87- Ver Ebeling, LKA, n. 70, v. 1,26.

88- Ver Falkenstein, 1931, p. 20.

89- Ver Gadd, 1925, v. 38, Plate 4, 81-82.

90- Ver Soden, W. von, Die Lexikalischen Tafelserien, p. 3, 1, VI, 41-44. 


\section{Referências Bibliográficas}

BAUER, T. Das Inschriftenwerk Assurbanipals. Leipzig: J.C. Hinrich, 1933. v. 2.

BORGER, R. Die Inschriften Asarhaddons, König von Assyrien. Archiv für Orientforschung, Beiheft 9. Graz:1956.

BOTTÉRO, J. Symptômes, signes, écritures en Mésopotamie ancienne. In: VERNANT, J.P. et al. (org.), Divination et Rationalité. Paris: Seuil, 1974.

BOUZON, E. Die Prophetenkorporationen In Israel und in Alten Orient. Ein Beitrag zur Geschichte der nebiistischen Bewegung (Diss. Auszug) Münster: 1969.

BOUZON, E. O Código de Hammurabi. Petrópolis: Vozes, 1987.

BRINKMAN, J.A. Materials and studies for Kassite history. Chicago: The Oriental Institute of the University of Chicago, 1976.

CRAGHAN, J.F. The ARM X 'Prophetic' Texts. Their Media, Style and Structure. Journal of the Ancient Near Eastern Society of Columbia University, 6. New York: 1974, p. 39-57.

CRAIG, J.A. Assyrian and Babylonian Religions Texts. Leipzig: J.C. Hinrich, 1895.

DOSSIN, G. Correspondance Féminine. Archives Royales de Mari. Paris: Librairie Orientaliste Paul Geuthner, 1978, v. 10 [abreviatura ARM X].

DOSSIN, G. e BOTTÉRO, J. et al. Textes Divers. Archive Royales de Mari. Paris: Librairie Orientaliste Paul Geuthner, 1964, v. 13 [abreviatura ARM XII].

DOSSIN, G. Sur le prophétisme a Mari. In: La Divination en Mésopotamie ancienne et dans les régions voisines. XIV Rencontre Assyriologique Internationale. Paris: PUF, 1966, p. 77-86.

DOSSING, G. Mémoires de la Mission Archéologique de Perse. Tome XVIII: Autres textes sumériens et accadiens. Paris: Librairie Emest Leroux, 1927.

EBELING, E. Keilschrifttexte aus Assur religiösen Inhalts. Leipzig: J.C. Hinrich, 1919. 2v. [abreviatura KAR].

EBELING, E. Literarische Keilschrifttext aus Assur. Berlin: Akademie Verlag, 1953 [abreviatura LKA].

EBELING, E. e MEISSNER, B. (org.) Reallexikon der Assyriologie. Berlin: Walter de Gruyter, 1938.

EBELING, E. Tod und Leben nach den Vorstellungen der Babylonier. Berlin: Walter de Gruyter, 1931 .

EDZARD, D. O. Altbabylonische Rechts - und Wirtschaftsurkunden aus Tell ed-Der im Iraq Museum, Baghdad. München: Verlag der Wissenschaften, 1970.

EDZARD, D. O. e FARBER. Répertoire Geographique des Textes Cuneiformes. Wiesbaden: Ludwig Reichert Verlag, 1974.

EDZARD, D. O. (org.) Reallexikon der Assyriologie. Berlin: Walter de Gnyter, 1976-1980.

ELLEMEIER, F. Prophetie in Mari und Israel. Herzberg: Verlag Erwin Jungfer, 1968.

FALKENSTEIN, A. Literatische Keilschriftexte aus Uruk. Vorderasiatische Abteilung der Staatlichen Museen. Berlin:1931.

GADD, C. J. Cuneiform Texts from Babylonian Tablets in the British Museum. London: The Trustees of British Museum, 1925, v. 38 [abreviatura CT 38].

GADD, C. J. Some Babylonian Divinatory Methods and their inter-relations. In: La Divination en Mésopotamie Ancienne. XIV Rencontre Assyriologique International Paris: PUF, 1966, p. 21-34.

GOETZE, A. Old Babylonian Omen Texts. Yale Oriental Series - Babylonian Texts. New Haven: Yale University Press, 1947, v.10 [abreviatura YOS 10]. 
GRAYSON, A. K. e LAMBERT, W.G. Akkadian Prophecies. Journal of Cuneiform Studies, 18, New Haven, 1964, p.7-30.

HAUSSIG, H. W. (org.) Worterbuchder Mythologie. Stuttgart: Ernst Nlett Verlag, 1965

JEAN, Ch. - F. Contrats de Larasa. Musée du Louvre - Textes Cuneiformes. Paris: Librairie Orientaliste P. Geuthner, 1926 [abreviatura TCL X].

KINGSBURY, E. C. A Seven day ritual in the Old Babylonian cult at Larsa. Hebrew Union College Annual 34, Cincinnati, 1963, p.1-28.

KUPPER, J. R. Correspondence de Bahdi-Lim. Archives Royales de Mari. Paris: Imprimerie Nationale, 1954 [abreviatura ARM VI].

KUPPER, J. R. Correspondance de Kibri-Dagan. Archives Royales de Mari III. Paris: Imprimerie Nationale, 1950 [abreviatura ARM III].

LABAT, R. Traité Akkadien de Diagnostics et pronostics médicaux. Brill, Leiden, 1951. v. 2

LODS, A. Une tablette inédite de Mari, interessante pour l'histoire ancienne du prophétisme semitique. In: ROWLEY, H.H. (org.), Studies in Old Testament Prophecy. Edimburgo: T and T Clark, 1950, p.10-103.

MEISSNER, B. Babylonien und Assyrien. Heildelberg: Carl Winter, 1925.

MORAN, W. L. New Evidence from Mari on the History of Prophecy. Biblica, 50, Roma, 1969, p.15.

NOORT, E. Untersuchungen zum Gottesbescheid in Mari. Kevelaer: Verlag Butzon und Bercker, 1977.

NÖTSCHER, F. Haus - und Stadtomina. Der Serie shumma âlu ina mêlê shakin. Orientalia, 31, Roma, 1928 , p.3-78.

NOUGAYROL, J., LAROCHE, E. et al. Ugaritica $V$ - Mission de Ras Shamra Tome XVI. Paris: Imprimerie Nationale, 1968.

OPPENHEIM, A.L. Ancient Mesopotamia. Chicago: The University of Chicago Press, 1976.

PARROT, A. Mari, une ville perdue. Paris: Je Sers, 1945.

PARROT, A. Mari capitale jabuleuse. Paris: Payot, 1974.

PETTINATO, G. Die Ölwahrsagung bei den Babyloniern. Roma: Istituto di Studi del Viciuo Oriente, 1966.

RENGER, J. Untersuchungen zum Priestertum der altbabylonischen Zeit. Zeitschrift für Assyriologie, 59, Berlin, 1969, p.104-230.

SACHS, A. J. e HUNGER, H. Astronomical Diaries and Related Textes from Babylonia. Wien: Verlag der Österreichischen Academie der Wissenschajten, 1988.

SCAEFFER, C. F. A. Mission de Ras Shamra. Paris: Librairie Orientaliste Paul Geuthner, 1939.

SCHEIL, V. Délégation en Perse-Mémoires. Paris: Ernest Leroux Éditeur, 1908.

SCHROEDER, O. Vordesasiatische Schriftdenkmäler der Königllichen Museen zu Berlin, Heft 16: Altbabylonische Briefe. Leipzig: J.C. Hinrich, 1917 [abreviatura VS 16].

SODEN, W. von. Introducción al Orientalismo Antiguo. Sabadell: AUSA, 1987.

SODEN, W. von. Verkündung des Gotteswillens durch prophetisches Wort in den altbabylonischen Briefen aus Mari. Welt des Orients 1 (1947-1952) p. 397-403.

SODEN, W. von. Die Lexikalischen Tatelserien der Babylonier und Assyrer in den Berliner Museen. vol 2: Die akkadischen Synony menlisten. Vorderasiatische Abteilung der Staatlichen Museen. Berlin: 1933.

SOLLBERGER, E. The Business and Administrative Correspondance under the Kings of Ur. Texts from Cuneiform Sources. New York: J.J. Augustin Publisher, 1966, v.1.

STARR, I. The Rituals of the Diviner. Malibu: Undena Publications, 1973.

STRONG, S. A. Proceedings of the Society of Biblical Archaeology XVII. Londres: 1895

THOMPSON, R. C. The Prisms of Esarhaddon and Ashurbanipal found at Nineveh, 1927-8.

London: Trustees of the British Museum, 1931. 
THUREAU-DANGIN, F. Lettres et Contrats de l'époque de la première dynastie babylonienne. Musée du Louvre. Département des Antiquités orientales. Paris: Librairie Orientaliste Paul Geuthner, 1973 [abreviatura: TCL 1].

WEIDNER, E. F. Handbuch der babylonischen Astronomie, v. 1: Der Babylonische Fixsterntrimmel. Leipzig: J. C. Hinrich, 1915.

WEIPPERT, M. Aspekte israelitischer Prophetie im Lichte verwandter Erscheinungen des Alten Orients. In: MAUER, G. e MAGEN, V. Ad bene et fideliter seminandum. Festgabe für Karlheinz Deller. Kevelaer: Verlag Butzon und Bercker, 1988, p. 287-319.

WISEMAN, D. J. The Vassal-treaties of Esarhaddon. Iraq, 20. London: 1958, p.10-101.

WEISSNER, B. Babylonien und Assyrien. Heildelberg: Carl Winter, 1925.

BOUZON, E. L'usage du transe extatique dans le processus de la divination en Babylone. Clássica, São Paulo, 4: 35-52, 1991.

RÉSUMÉ: Cet article traite d'une série de textes en écriture cunéiforme de la Babylone antique pendant plusieurs périodes. On sait, par ces tablettes, qu'outre la divination déductive, sans doute la plus abondamment témoignée, il y a eu un autre type de contact avec la divinité: la divination "inspirée", par laquelle les dieux communiquaient leur message à un intermédiaire entré entranse. Dans les textes connus cet intermédiaire recevait le tritre de mahhûm ou muhhûm pour un homme et mahhûtum ou muhhûtum pour une femme.

MOTS CLÉS: Babylone, divination, transe extatique, cunéiformes. 